\title{
Parental Verbal Communication and Sexual Knowledge of Senior Secondary School Students in South East, Nigeria
}

\author{
CJ Orji ${ }^{1,2^{*}}$, SU Arinze-Onyia ${ }^{1,2}$, CN. Obionu ${ }^{3}$
}

\author{
OPEN ACCESS \\ Citation: CJ Orji, SU Arinze-Onyia, CN. \\ Obionu. Parental Verbal Communication \\ and Sexual Knowledge of Senior \\ Secondary School Students in South East, \\ Niger. Ethiop J Health \\ Sci.2017;29(4):477.doi:http://dx.doi.org/ \\ 10.4314/ejhs.v29i4.9 \\ Received: March 07, 2019 \\ Accepted: May 21, 2019 \\ Published: July 1, 2019 \\ Copyright: (C) 2019 CJ Orji., et al. This is \\ an open access article distributed under \\ the terms of the Creative Commons \\ Attribution License, which permits \\ unrestricted use, distribution, and \\ reproduction in any medium, provided the \\ original author and source are credited. \\ Funding: Nil \\ Competing Interests: The authors \\ declare that this manuscript was approved \\ by all authors in its form and that no \\ competing interest exists. \\ Affiliation and Correspondence: \\ ${ }^{1}$ ESUCOM Healthcare Research \\ Initiative \\ ${ }^{2}$ Enugu State University College of \\ Medicine Enugu \\ *Email: Chinonyelu@yahoo.com, \\ Orjichinonyelu@gmail.com
}

\section{ABSTRACT}

BACKGROUND: Parental verbal communication may influence the sexual knowledge of senior secondary school students in Enugu State, Nigeria.

METHODS: This study utilized a school based cross-sectional study design and was conducted across the six education zones of Enugu State using three-stage sampling technique. A total of 400 respondents completed the interviewer administered questionnaires on their socio-demographics, sexual knowledge and parents' information on verbal communication skills. Obtainable knowledge scores for sexuality ranged between 0-10; scores of 1-5 were classified as poor and 6-10 as good. Data analysis for the quantitative data was done using IBM SPSS; version 22. Chi square test of statistical significance and multivariate analysis using binary logistic regression were used in the analysis, and the level of significance was set at a p value of less than 0.05 .

RESULTS: Out of the 400 respondents, $55.5 \%$ were girls. The mean age (SD) of the respondents was $15.9 \pm 1.3$ years. Although $15.5 \%$ and $8.8 \%$ of the respondents were very comfortable discussing sexually related matters with their mothers and fathers only $34.8 \%$ and $16.0 \%$ of mothers and fathers were comfortable discussing such matters with the respondents. Less than half of the respondents (42.5\%) had good sexual knowledge. Verbal sexual communication between parents and respondents and age above 16 years were found to be predictors of good sexual knowledge.

CONCLUSIONS: Poor parental verbal communication led to the poor knowledge of sexuality among the respondents. Parents should be encouraged to discuss sexuality matters with their children.

KEYWORDS: Parents, Verbal communication, Sexual Knowledge, Students, Nigeria

\section{INTRODUCTION}

In 1994, at Cairo, the International Conference on Population and Development (ICPD) with one hundred and seventy-nine governments in attendance endorsed a ground breaking programme of action which recognized the important role of young people in development (1). Eighteen years later in New York, it passed a 
resolution which recognized the rights, duties and responsibilities of parents and other persons legally responsible for adolescents to provide appropriate direction and guidance on sexual and reproductive health matters in a manner consistent with the evolving capacities of the adolescents (2).

Worldwide, there are an estimated 1.8 billion young people making up a fourth of the entire human population of 7.3 billion. Nine out of every ten young person live in the developing countries (1). Nigeria being the most populous black nation on earth and the sixth most populous in the world boasts of an estimated population of 177.5 million (3). According to the population and housing census carried out in 2006, young people aged $10-24$ years constitute $31.7 \%$ of the total population of the country with nearly equal proportions of males and females (50.1\% males and $49.9 \%$ females) (4).

Young people worldwide are faced with sexual and reproductive health issues. Various stakeholders tend to withhold sexuality information from young people mainly as a result of negative traditional and socio-cultural beliefs (5). Studies in Nigeria have shown that there is a general tendency for parents and other adults to be secretive about sensitive developmental issues such as sexual and reproductive health issues (6). Poor access to reliable, adequate and valid information about sexuality, and its dimensions are a norm in all regions of Nigeria and Enugu State is not left out. Most parents still fear that providing sex education to their young people will encourage them to try out sex and may increase risky sexual behavior (7).

The National HIV/AIDS Reproductive Health Plus Survey of 2012 (NARHS) generally showed low level of health communication on reproductive health issues among the Nigerian population(8). The finding that only $17 \%$ of young persons (15-19 years) were comfortable to discuss sexual matters with their mothers and $10 \%$ with their fathers has a significant implication for the acquisition of correct information on sexuality and related issues by young people (8). The Nigeria Demographic and Health Survey of 2013 revealed that $31 \%$ of adults had discussed sexually transmitted infections (STI) and family planning
$(7 \%)$ with their male wards. In the same vein, $35 \%$ of adults had discussed STI and 8\% had discussed family planning with their female wards (9).

This study aimed to establish a relationship between parental verbal communication and knowledge of sexuality among senior secondary school students in Southeast, Nigeria.

\section{METHODS}

This was a school based descriptive crosssectional study carried out in Enugu State, Southeast Nigeria between September and October 2016. Co-educational schools were used to improve representativeness of the study population.

Inclusion criteria: The study population were senior secondary school students between the ages of 12 and 20 years from co-educational schools in Enugu State.

Exclusion criteria: Married students and students who did not wish to participate were excluded from the study.

The sampling technique: The study area had 314 public secondary schools and 210 private secondary schools (10). There were 486 coeducational secondary schools in all. For the operations of the Ministry of Education, the state is divided into six zones; namely, Agbani, Awgu, Enugu, Nsukka, Obollo-afor and Udi. A minimum sample size of 290 was determined using the fisher's formula. Using a correction factor of $20 \%$ for non-response rate increased the sample size to 363. Finally, 400 respondents were included in the study.

A three stage sampling technique was used:

Stage 1: Simple random sampling technique through balloting was used to select one local government area from each of the six education zones in Enugu State.

Stage 2: Simple random sampling by balloting was used to select 10 co-educational schools from the forty-three co-educational schools in the six LGAs respectively. Proportional allocation in the ratios of $1: 1: 1: 1: 2: 4$ was used to select 1 school each from Enugu-East, Nkanu-West, Udenu, and Oji-River LGA, 2 schools from Nsukka LGA and 4 schools from Udi LGA. 
Stage 3: Systematic sampling technique was then applied to select the students. Equal allocation was used to select 40 students from each school. Selection of students was done at the assembly grounds using the total number of senior secondary school students present on the day of data collection as the sampling frame. The sampling interval was determined by dividing the sampling frame in each school by the sample size of 40 . Thus, every $\mathrm{n}^{\text {th }}$ student was recruited for the study. The index student was selected by simple random sampling technique through balloting. This was done for all the selected schools.

The study instruments: A pre-tested semistructured interviewer-administered questionnaire was used for quatitative data collection in this survey. This instrument was adapted from the World Health Organization questionnaire template for assessing the sexual and reproductive health status of young people globally.(11) The questionnaire contained 3 sections: Section 1 obtained information on the socio-demographic characteristics of the students and their parents. Section 2 was used to collect data on sexual knowledge of the respondents and section 3 helped to gather data on parental verbal factors from the respondents. The World Health Organization Questionnaire was adopted for this study to assess the sexual knowledge of the adolescents. Parental verbal communication and sexual knowledge of the respondents were assessed using seven and five variables respectively. A correct response to each knowledge variable was determined by the respondent's ability to answer the question. Each correct response was scored one mark and a nonresponse or wrong response was scored a zero mark. These scores were added up to give a total knowledge sum for each respondent. A sum score of fifty percent and above was used as a cut-off for knowledge. While scores above 50\% were graded as good verbal communication and sexual knowledge, scores below 50\% were graded as poor parental verbal communication and sexual knowledge.
Ethical permit: Ethical permission was obtained from the Ethics Committee of the Enugu State University Teaching Hospital, Parklane Enugu, while informed consent was obtained from the students with approval from the Enugu State Ministry of Education.

Data collection: The senior secondary school students' in these schools were invited to be part of the study. Pre-tested interviewer-administered questionnaire was used to collect data from respondents. Contents of the questionnaire included demographical variables, sexual knowledge and parental verbal sexual communication.

Statistical Analysis: Data collection and editing of questionnaires was done manually by the investigator to detect omissions and ensure uniform coding. Uncompleted questionnaires were discarded. The analysis was done using IBM SPSS Statistical Package version 22. Descriptive statistical analysis (frequencies and percentages) were used for categorical variables. While sociodemographic factors and parental verbal communication were the independent variables, sexual knowledge was the dependent variable in this study. Chi square test of significance and multivariate analysis using binary logistic regression were used to determine the relationship between parental verbal and sociodemographic factors and sexual knowledge of the respondents in the analysis. The level of statistical significance was determined by a $\mathrm{p}$ value of less than 0.05 .

\section{RESULTS}

Table 1 shows the socio-demographic characteristics of the respondents. The majority were females $(55.5 \%)$, not in a relationship $(68.5 \%)$, and within the $15-19$ years $(86.8 \%)$ age category. Their mean age and standard deviation was $15.9 \pm 1.3$ years. Over half of the respondents $(54.3 \%)$ had an average school performance which was determined by using teachers' result sheets for the previous two terms, and a greater proportion $(76.8 \%)$ were living with both parents.

DOI: http://dx.doi.org/10.4314/ejhs.v29i4.9 
Table 1: Socio-demographic characteristics of respondents

\begin{tabular}{llc}
\hline Variable & $\begin{array}{l}\text { Frequency } \\
(\mathrm{n}=400)\end{array}$ & Percent (\%) \\
\hline Age of respondents in years & 48 & 12.0 \\
$12-14$ & 347 & 86.8 \\
$15-19$ & 5 & 1.2 \\
$20-24$ & 15.9 years \pm 1.3 & \\
Mean \pm SD (years) & & \\
Sex & 222 & 55.5 \\
Female & 178 & 44.5 \\
Male & & \\
Class * & 166 & 41.5 \\
SS 1 & 126 & 31.5 \\
SS2 & 108 & 27.0 \\
SS3 & & \\
Academic performance (last two term & & 41.7 \\
results from teacher) & 167 & 54.3 \\
$\quad$ Above average & 217 & 4.0 \\
Average & 16 & 76.8 \\
$\quad$ Below average & & 15.8 \\
Respondent lives with & 307 & 7.4 \\
Both parents & 63 & \\
$\quad$ One parent & 30 & 68.5 \\
$\quad$ Relatives & & 31.5 \\
Current relationship status of & 274 & 1.5 \\
respondent & 146 & \\
$\quad$ Not in any relationship & & \\
In a relationship & 346 & \\
Importance of religion to respondent & 50 & \\
$\quad$ Very important & 4 & \\
Important & & \\
$\quad$ Not important & & \\
\hline
\end{tabular}

*SS 1,2,3 means Senior Secondary 1,2 3

Table 2 depicts the knowledge of contraception and fertility among the respondents. Even though 280 respondents $(70.0 \%)$ had never heard of contraception, $66 \%$ reportedly had seen a condom. Less than a third of the respondents (30\%) agreed that condom was the most suitable method of preventing pregnancy. Only $45.5 \%$ of the respondents knew that a girl could get pregnant if she engaged in sexual intercourse midway between her menstrual periods. However, a similar proportion reported that a girl could still get pregnant while on contraceptive pills $(37.8 \%)$ or if her partner used the withdrawal method (33.8\%).
Table 3 shows that over $90 \%$ of the respondents had heard of STI, only $29.2 \%$ knew that condom was an effective way of preventing STIs. However, $62.0 \%$ knew that painful micturition and swelling/boil at the genitalia (48.5\%) were known symptoms of STI. Having unprotected sex $(88.3 \%)$ was noted as the commonest way of contracting STIs. HIV/AIDS (56.3\%), and gonorrhea $(50.0 \%)$ were the most commonly reported STIs noted by the respondents. Less than half of the respondents $(42.5 \%)$ were found to have good sexual knowledge. 
Table 2: Knowledge of contraception and fertility of the respondents

\begin{tabular}{|c|c|c|}
\hline Variable & Frequency $(n=400)$ & Percent $(\%)$ \\
\hline \multicolumn{3}{|l|}{ Ever heard of contraception } \\
\hline Yes & 120 & 30.0 \\
\hline No & 280 & 70.0 \\
\hline \multicolumn{3}{|l|}{ Ever seen a condom } \\
\hline Yes & 264 & 66.0 \\
\hline No & 136 & 34.0 \\
\hline \multicolumn{3}{|l|}{ Known contraceptive methods** } \\
\hline The pill & 109 & 27.3 \\
\hline Safe period & 104 & 26.0 \\
\hline Withdrawal method & 92 & 23.0 \\
\hline Male/female sterilization & 61 & 15.3 \\
\hline The injectable & 50 & 12.5 \\
\hline Intrauterine device & 43 & 10.8 \\
\hline Implant & 39 & 9.8 \\
\hline \multicolumn{3}{|l|}{$\begin{array}{l}\text { Most suitable method of } \\
\text { contraceptive for respondents }\end{array}$} \\
\hline Condom & 203 & 50.8 \\
\hline Periodic abstinence & 107 & 26.8 \\
\hline Withdrawal & 43 & 10.8 \\
\hline Injection & 21 & 5.3 \\
\hline Pill & 17 & 4.3 \\
\hline Emergency pill & 8 & 2.0 \\
\hline \multicolumn{3}{|l|}{ A girl can get pregnant if $* * \ldots$} \\
\hline Her partner uses a condom & 208 & 52.0 \\
\hline She has sex in between her periods & 182 & 45.5 \\
\hline She takes the contraceptive pill & 151 & 37.8 \\
\hline $\begin{array}{l}\text { Her partner removes his penis from } \\
\text { her vagina before ejaculation }\end{array}$ & 135 & 33.8 \\
\hline
\end{tabular}

Table 4 indicates that while menstruation (48.3\%) and pregnancy $(42.3 \%)$ were the most talked about sexually related issues with mothers, STIs $(21.8 \%)$ and couple relationships (18\%) were the most talked about with fathers. A higher proportion of mothers $(34.8 \%)$ were more comfortable about discussing sexually related matters with the respondents than their fathers $(15.5 \%)$; a similar proportion of respondents were comfortable discussing such issues with their mothers $(37.5 \%)$ than with their fathers $(33.8 \%)$. When parental verbal communication was graded into good and poor, only about a third of the parents were found to be communicating with their wards. 
Table 3: Knowledge of Ssexually transmitted infections among the respondents

\begin{tabular}{lll}
\hline Variable & Frequency $(\mathbf{n = 4 0 0 )}$ & Percent (\%) \\
\hline Ever heard of STI & 360 & 90 \\
Yes & 40 & 10 \\
No & & \\
People get infected with STI when** & 149 & 37.3 \\
They use a condom & 126 & 31.5 \\
They chose a sexual partner that looks & & \\
healthy & 101 & 25.3 \\
They have sex with a known person & 82 & 20.5 \\
They take antibiotics before sex & 76 & 19.0 \\
Known ways of preventing STI & 283 & 70.8 \\
Abstinence & 117 & 29.2 \\
Condom & & \\
Ways of contracting STIs ** & 353 & 88.3 \\
Unprotected sex & 270 & 67.5 \\
Blood and blood products & 254 & 63.5 \\
Needles and syringes & 250 & 62.5 \\
Mother to child & 112 & 28.0 \\
Sharing toilets & 56 & 14.0 \\
Mosquito bites & 52 & 13.0 \\
Coughing and sneezing & 18 & 4.5 \\
Shaking hands & & 66.5 \\
Symptoms of STI** & 256 & 62.0 \\
Weight loss & 248 & 48.5 \\
Burning area when passing urine & 194 & 43.0 \\
Swelling/boil at the genitalia & 172 & 41.0 \\
Body rash & 164 & \\
Discharge from genital area & & \\
\hline
\end{tabular}

**multiple responses were encouraged

As shown in Table 5, sexual knowledge was significantly higher among respondents who were greater than 16 years of age and were communicating with their parents $\mathrm{p}<0.05$. Females who were greater than 16 years were more likely to have better sexual knowledge than males. However, this finding was not statistically significant. 
Table 4: Verbal sexual communication between respondents and their parents

\begin{tabular}{|c|c|c|}
\hline Variable & $\begin{array}{l}\text { Frequency } \\
(\mathrm{n}=\mathbf{4 0 0})\end{array}$ & Percentage (\%) \\
\hline \multicolumn{3}{|c|}{$\begin{array}{l}\text { Verbal Sexual Communication between respondents and } \\
\text { parents }\end{array}$} \\
\hline \multicolumn{3}{|l|}{ Parents most talked to about things concerning you } \\
\hline Mother & 236 & 59.6 \\
\hline Father & 164 & 40.4 \\
\hline \multicolumn{3}{|c|}{ Frequency of talking to mother about sex related issues } \\
\hline Rarely & 251 & 62.8 \\
\hline Often & 149 & 37.2 \\
\hline \multicolumn{3}{|c|}{ Frequency of talking to father about sex related issues } \\
\hline Rarely & 301 & 75.5 \\
\hline Often & 99 & 24.5 \\
\hline \multicolumn{3}{|c|}{ Most common sexual topics discussed with mother**: } \\
\hline Sexually transmitted Diseases and HIV/AIDS & 156 & 39.0 \\
\hline Pregnancy & 169 & 42.3 \\
\hline Menstruation & 193 & 48.3 \\
\hline \multicolumn{3}{|l|}{ Most common sexual topics discussed with father** } \\
\hline When to start having sex & 49 & 12.3 \\
\hline Sexually Transmitted Diseases and HIV/AIDS & 87 & 21.8 \\
\hline Couple relationships & 72 & 18.0 \\
\hline \multicolumn{3}{|c|}{ Comfort of mother while discussing sex with respondents } \\
\hline Uncomfortable & 138 & 34.6 \\
\hline Very comfortable & 139 & 34.8 \\
\hline She does not talk & 123 & 30.6 \\
\hline \multicolumn{3}{|c|}{ Comfort of father while discussing sex with respondents } \\
\hline Uncomfortable & 222 & 55.5 \\
\hline Very comfortable & 64 & 16.0 \\
\hline She does not talk & 114 & 28.5 \\
\hline \multicolumn{3}{|c|}{ Comfort of young person while discussing sex with mother } \\
\hline Uncomfortable & 144 & 36.0 \\
\hline Very comfortable & 62 & 15.5 \\
\hline He does not talk & 194 & 48.5 \\
\hline \multicolumn{3}{|c|}{ Comfort of young person while discussing sex with father } \\
\hline Uncomfortable & 184 & 46.1 \\
\hline Very comfortable & 35 & 8.8 \\
\hline He does not talk & 181 & 45.1 \\
\hline
\end{tabular}

$* *$ multiple responses encouraged

Table 5: Predictors of good sexual knowledge among the respondents

\begin{tabular}{|c|c|c|c|c|}
\hline Variable & Odds Ratio & P value & \multicolumn{2}{|c|}{$\begin{array}{l}\text { 95\% Confidence Interval for } \\
\text { the Odds Ratio } \\
\text { Lower Upper }\end{array}$} \\
\hline Verbal sexual communication & & & & \\
\hline Communicating & 1.907 & 0.03 & 0.293 & 0.804 \\
\hline Not communicating & 1 & & & \\
\hline Age & & & & \\
\hline$\geq 16$ years & 2.68 & 0.003 & 0.193 & 0.719 \\
\hline$<16$ years & 1 & & & \\
\hline Gender & & & & \\
\hline Female & 1.480 & 0.149 & 0.870 & 2.519 \\
\hline Male & 1 & & & \\
\hline
\end{tabular}

DOI: http://dx.doi.org/10.4314/ejhs.v29i4.9 


\section{DISCUSSION}

Less than half of the respondents in this study had good knowledge about sexuality. These findings are clearly evidenced from the results contained within the NDHS survey of 2013 which equally revealed very poor communication between parents and their wards (12). A similar study carried out in Ethiopia and Kenya revealed that only about a third of all the respondents had passable knowledge about their sexuality (13). The low level of sexual knowledge of these young people can be explained by the fact that parents may not be discussing sexuality in the home because they may perceive that it may encourage young ones to try out sex. Additionally, sexuality education is not fully taught in an overwhelming majority of secondary schools despite recommendations and approvals for it (14).

Even though a higher proportion of the respondents in the survey $(90 \%)$ had heard about STIs and the majority could correctly identify the modes of transmission as well as the common complaints in people with STI, only about half $(56.3 \%)$ knew that HIV/AIDS was an example of a sexually transmitted disease. This is a worrisome development because young women alone make up $72 \%$ of all the global burden of HIV/AIDS in subSaharan Africa (2). However, this finding is quite different from that of a similar study carried out in River State, Nigeria, which revealed that $93.6 \%$ of all the respondents had heard about STIs and most of the students knew that HIV was a type of STI (14). The general awareness among students in Rivers state, Nigeria that HIV was a form of STI could be attributed to the robust ongoing STI health promotion campaigns on the media in the State. Up until the last survey of National Agency for the Control of AIDS (NACA) sentinel survey in 2015, Rivers was the state with the highest prevalence of HIV/AIDS in Nigeria.

On prevention of sexually transmitted infections, the majority of the respondents in the survey $(70.2 \%)$ knew that abstinence was a major protective factor, while less than a third (29.8\%) of the respondents knew that using condoms during sex was also a protective factor.The finding of this study is comparable to a study carried out in Anambra State, Nigeria, which revealed that about a third of the respondents knew that condom could protect against STI, and only $38.6 \%$ also knew that abstinence was a protective factor (15). The United Nations General Assembly Special Session
(UNGASS) has ascertained that the disparity in knowledge about STI prevention among adolescent boys and girls could be linked to gender, education, household wealth and place of residence and may be a pointer to what areas receive the most emphasis in health promotion programmes, both to the presenters/sources and the receivers/consumers worldwide (16). This finding shows that while media campaigns often receive credit for increasing population awareness of health problems and situations, creating a level of knowledge or understanding that may influence action could possibly only be achieved through educational programmes (17).

On fertility, less than half of the respondents knew that a girl was likely to get pregnant if she had sex in between her periods. This result is much higher than the result of the NDHS 2013 where only 19\% of all women were aware of the fertile period of a woman (12). Similar studies carried out in Northern Nigeria, Southeast Nigeria, and South Africa revealed that less than $3.1 \%, 30 \%$ and $11 \%$ of the respondents respectively were aware of the fertile period in a woman's cycle. $(15,18,19) \quad$ This finding could probably be due to the low level of sexuality information given to students while in schools.

Knowledge of contraceptives was found to be poor in this study. The condom awareness rate is in keeping with the results of the NARHS Plus survey of 2012 with recorded national rates of $64.3 \%$ in the 15-19 years' age group. Similar findings were noted in a study carried out in Onitsha, Nigeria, with awareness rates of $72.9 \%$ among in school youths and $68.1 \%$ among out- of school youths $(7,15)$. However, this poor knowledge about contraceptives is not in keeping with a study carried out in Rivers State, Nigeria, where over $80 \%$ of the respondents had heard about contraceptives (14). This difference in contraceptive knowledge may be due to cultural differences in the geographic locations of the respondents.

Verbal communication about sex by the respondents and their parents was found to happen rarely. Only a third $(33.0 \%)$ of all respondents were communicating with their parents on sexuality matters. This proportion is similar to what was obtained in a study carried out in Ethiopia which revealed that only $36.8 \%$ of the participants had ever discussed at least two sexual and reproductive health issues with their parents (20). Studies from 4 different sub-Saharan African cities revealed that the proportion of adolescents reporting having discussed

DOI: http://dx.doi.org/10.4314/ejhs.v29i4.9 
sexuality matters with their parents ranged from $8 \%$ - 38\%, in Tanzania, $27 \%$ in Northern Nigeria, $12 \%$ in Imo State, Nigeria and $10.5 \%$ in Anambra State, Nigeria (21-24). This reluctance on the part of the parents and their children may well be associated with our cultural values where it remains almost a taboo to discuss such matters.

In most families, mothers were more likely to talk to respondents about sexuality than fathers. A similar study carried out in a state owned junior secondary school in Northern Nigeria revealed that only $27 \%$ and $5 \%$ of sexually active students reported communication with mothers about HIV/AIDS and sex respectively while a study executed in Imo State, Nigeria, had reported that $65 \%$ of the mothers had discussed sexuality topics with their children. (21-22) Another study in Anambra State, Nigeria, documented that only $10.5 \%$ of adolescents who had discussed such topics had ever engaged in sexual intercourse (23). It is crucial to understand that open and honest dialogue ensues when parents starts communicating with their children from an early age (22).

This study revealed that parental-adolescent communication was a predictor of good sexual knowledge $(\mathrm{AOR}=1.907, \mathrm{p}$ value $=0.03)$. This result is in keeping with the results of a study in Vietnam whereby good sexual knowledge of the young people was associated with the frequency of 'talk' (AOR $=2.863, \mathrm{p}$ value $=0.016$ ) and comfortability of discussing sexually related issues with parents with $($ AOR $=3.693 \mathrm{p}$ value $=0.003)(24)$. The notable barriers to communication include religious barriers, residual traditional barriers, shame, lack of communication skills and excessive reliance on sexeducation and school teachers (25). Being older than 16 years was the only other predictor of good sexual knowledge.

This study was limited to young people who were actively enrolled and attending school. This limits the extent to which the finding can be generalized to the wider community of young people who may not be in school. Other factors (characteristics) of the family that might affect youths' sexual knowledge and psychosocial health were not fully explored. Lastly, taking into account that the influences of sexual knowledge are multifactorial, the exact single factor that can lead to enhanced sexual knowledge among young people may be difficult to determine.
Generally, the sexual knowledge of the respondents was found to be poor. Even though the awareness of sexually transmitted infections and its risk factors, symptoms and prevention were found to be high among the respondents, their knowledge of fertility and modern methods of contraception was low. For the fact that these young people were not well informed about sex and sexually related matters, a good proportion of them had no appreciation of the risks involved in having unprotected sexual intercourse, or the benefits of using contraceptives. However, this study revealed that parental verbal communication influenced the sexual knowledge of the respondents.

\section{ACKNOWLEDGEMENTS}

The authors wish to thank the management of Enugu State University Teaching Hospital, Enugu as well as the staff and management of Enugu State Ministry of Education who gave the required permissions to use schools. Our gratitude also goes to the principals, teachers and students of all the secondary schools that participated in the study.

\section{REFERENCES}

1. United Nations Population Fund. State of the World Population: The Power of 1.8 Billion, New York: UNFPA 2014.

2. ICPD. Department of Economic and Social Affairs, United Nations (UN) Population Division Report of the International Conference on Population and Development, New York: UN, 1994.

3. Population Reference Bureau and Center for Population Options 2014. World Data Sheet. Accessed March 24, 2019.

4. National Population Commission of Nigeria. Population and Housing Census 2006.Accessed January 15, 2019.

5. Allen S, Perez-cruz G, Vail T. Meeting the Sexual and Reproductive Health Needs of Young People in Nigeria: $A$ Guide for Action.2009;Accessed January 15, 2019.

6. Federal Ministry of Health Nigeria (2014). National Agency for the Control of AIDS (NACA).Global AIDS Response Country Progress Report. 2014.

7. Adedimiji AA, Omolulu FO, Odutolu O.HIV risk perception and constraints to protective

DOI: http://dx.doi.org/10.4314/ejhs.v29i4.9 
behavior among young slum dwellers in Ibadan, Nigeria, Journal of Health, Population and Nutrition.2007;25(2):146-157. Accessed January 3, 2019.

8. Federal Ministry of Health Nigeria. National HIV and AIDS Reproductive Health Survey, 2012(NARHS Plus). Federal Ministry of Health, Abuja, Nigeria.

9. National Population Commission (NPC) and ICF Macro (2013), National Demographic and Health Survey 2014.National Population Commission and ICF Macro, Abuja.

10. Enugu State Ministry of Education. PostPrimary School Management Board, 2015.Ministry of Education Enugu State.

11. Clealand J. Illustrative questionnaire for interview-surveys with young people. Sexual and Reproductive health of adolescents. World Health Organization. National Population Commission (NPC) and ICF Macro (2013), National Demographic and Health Survey 2014. National Population Commission and ICF Macro, Abuja.

12. Biddlecom A, Awusabo - Asare K, Akinrinola B. Role of Parents in Adolescent Sexual Activity and Contraceptive Use in Four African Countries. International Perspectives on Sexual and Reproductive Health2009;35(2):72-81. Accessed January 21, 2019.

13. Agunwa CC, Aniebue UU, Aniebue PN. Sexual Behavior and Contraceptive Use Among Female Students in a Rural Community in South -South Nigeria. Jour. of Experimental Research.2014;2(2):65-72. Accessed January 3, 2019.

14. Adogu P, Nwabueze A,UdigweG, Nwabueze AS, Adinma ED, Ubajaka CF, Onwasigwe C. Sexual health Knowledge, attitude and risk perception among in-school and out-of school adolescents in Onitsha, Anambra State, Nigeria. J.of Pub.Health. 2014; 10(1) 2430. DOI 10.12908/SEEJPH-2014-25

15. United Nations Children's Fund. Towards an AIDS free Generation-Children and AIDS: Sixth Stocktaking Report,2013; New York,NY:UNICEF,2013;11-20.

16. Community partnerships for older adults. Evaluating changes in public awareness. Accessed January 4, 2016.

17. Adekunle LA, Ricketts OZ,Ajunwon AJ, Ladipo O. Sexual and Reproductive health knowledge, behaviors and education needs of in school adolescents in Northern Nigeria. AFR $J$ Reprod Health. 2009;13(1):37-9.

18. Ibaya GA, Amoko DH, Ncayana DJ. Adolescents,sexual behaviors, knowledge and attitude to sexuality among school girls in Transkei, South Africa. East AFR med J.1996;73(1):95-100.

19. Ayalew M, Mengistie B, Semahegn A. Adolesce nt-parent communication on sexual and reproductive health issues among high school students in Dire Dawa, Eastern Ethiopia :a cross sectional study. Reproductive Health Jour. 2014; 11(1):77-90. Assessed February 20,2019

20. Kawai K, Kaaya SF, Kajula L. Parents' and teachers' communication about HIV and sex in relation to the timing of sexual initiation among young adolescents in Tanzania. Scand $J$ Public Health. 2008;36(38):879-88 Accessed Feburary 19, 2019.

21. Mathew RM, Shugaba AI, Ogala WN. Parentsadolescents

Communication and HIV/AIDS in Jos North Lo cal Government Area, Plateau State, Nigeria. Journal of Medical Sciences.2006;6(1):537-45. Accessed January 21, 2019.

22. Opara PI, Eke GK, Akani NA. Mothers perception of sexuality education for children. Nigerian Journal of Medicine.2010;19(2):16872. Accessed January 22, 2019.

23. Udigwe IB, Adogu PO, Nwabueze AS, Adinma ED, Ubajaka CF, Onwasigwe C. Factors Influencing Sexual Behavior among Female Adolescents in Onitsha, Nigeria. Open Journal of Obstetrics and Gynecology. 2014;1(4):987995.

24. Kaljee L, Green M, Lerdboon P. Parental-youth communication and concordance between parents and adolescents on reported engagement in social relationships and sexually intimate behaviors in Ha Noi and Khanh Hoa Province, Viet Nam. J Adolescent Health.2011;48(3):268274.doi: 10.1016. Assessed January 21, 2019.

25. Davis AN, Gahagan JC, George C. Everyone just keeps their eyes closed and their fingers crossed. Sexual health communication among black parents and children in Novo Scotia, Canada. International Journal for Equity in Health. 2013; 1(1):1215-1219.Assessed February 19,2019. 